\title{
Tissue Doppler indexes of left ventricular systolic function in relation to the pulsatile and steady components of blood pressure in a general population
}

\author{
Wojciech Sakiewicz ${ }^{a}$, Tatiana Kuznetsovab ${ }^{b}$, Malgorzata Kloch-Badelek', Jan D'hooge ${ }^{\text {, }}$ \\ Andrew Ryabikove, Katarzyna Kunickaa , Ewa Swierblewska ${ }^{a}$, Lutgarde Thijs ${ }^{b}$, Yu Jin ${ }^{b}$, \\ Magdalena Losterc, Sofia Malyutina ${ }^{\mathrm{e}}$, Katarzyna Stolarz-Skrzypek ${ }^{c}$, Kalina Kawecka-Jaszcz', \\ Krzysztof Narkiewicz ${ }^{a}$, and Jan A. Staessen ${ }^{b, f}$, on behalf of the European Project On Genes in \\ Hypertension (EPOGH) Investigators
}

Objectives: To our knowledge, no population study described the association of the radial and longitudinal components of left ventricular strain with blood pressure (BP) components in continuous analyses. We therefore investigated these associations in participants randomly recruited from the general population in the framework of the family-based European Project on Genes in Hypertension.

Methods: In 334 participants (55.4\% women; mean age, 43.6 year), using tissue Doppler imaging (TDI), we measured the end-systolic longitudinal strain (mean $20.9 \%$ ) and peak systolic strain rate $\left(1.29 \mathrm{~s}^{-1}\right)$ from the basal portion of the left ventricular inferior and posterior free walls and radial stain $(51.1 \%)$ and strain rate $\left(3.40 \mathrm{~s}^{-1}\right)$ of the left ventricular posterior wall. Models included in addition to covariables and confounders both SBP and DBP or both pulse pressure (PP) and mean arterial pressure (MAP). Effect sizes were expressed per 1-SD increase in BP.

Results: Longitudinal strain $(-0.62 \% ; P=0.04$ and $-0.64 \%$; $P=0.007)$, but not strain rate, decreased with DBP and MAP. Radial strain (4.0 and $-3.4 \% ; P \leq 0.001)$ and strain rate $\left(0.38\right.$ and $\left.-0.18 s^{-1} ; P \leq 0.04\right)$ independently increased with SBP and decreased with DBP. Accordingly, radial strain $(2.9 \% ; P<0.0001)$ and strain rate $\left(0.22 \mathrm{~s}^{-1} ; P=0.0005\right)$ increased with higher $P P$, but were not related to MAP.

Conclusion: In the general population, BP is an independent determinant of left ventricular systolic function as measured by TDI. Radial function increased with PP, the pulsatile BP component, whereas longitudinal function decreased with the steady component of BP as expressed by MAP or DBP.

Keywords: blood pressure, left ventricular function, population, strain

Abbreviations: BP, blood pressure; EPOGH, European Project on Genes in Hypertension; MAP, mean arterial pressure; PP, pulse pressure; RWT, relative wall thickness; SPEQLE, Software Package For Echocardiographic
Quantification LEuven; TDI, tissue Doppler imaging; VIF, variance inflation factor; WHR, waist-to-hip ratio

\section{INTRODUGTION}

A ge-related stiffening of the large arteries leads to an increase in SBP. The heart typically adapts to confront higher earlier and later systolic loads by both hypertrophy and left ventricular stiffening. Hypertensive patients usually present with concentric remodeling or concentric left ventricular hypertrophy, but have a normal-sized left ventricular chamber and normal or even slightly enhanced ejection fraction. However, previous studies in hypertensive patients showed a reduced left ventricular longitudinal and midwall fractional shortening as measured by echocardiography [1-5] or MRI [6]. Thus, ejection fraction, which reflects only left ventricular cavity emptying, may be insensitive to detect early impairment of systolic function in response to an increased afterload. Using modern echocardiographic techniques, such as tissue Doppler imaging (TDI) or speckle tracking, one can evaluate how the functional adaptation of the left ventricle to increased cardiac load differs among patients. On the basis of color Doppler myocardial imaging, onedimensional regional longitudinal and radial strain and

\footnotetext{
Journal of Hypertension 2012, 30:403-410

${ }^{a}$ Hypertension Unit, Department of Hypertension and Diabetology, Medical University of Gdansk, Gdansk, Poland, 'bStudies Coordinating Centre, Division of Hypertension and Cardiovascular Rehabilitation, Department of Cardiovascular Disease, University of Leuven, Leuven, Belgium, 'First Department of Cardiology and Hypertension, Jagiellonian University Medical College, Cracow, Poland, 'Division of Cardiovascular Imaging and Dynamics, Department of Cardiovascular Disease, University of Leuven, Leuven, Belgium, e Institute of Internal Medicine, Novosibirsk, Russian Federation and fDepartment of Epidemiology, University of Maastricht, Maastricht, The Netherlands Correspondence to Tatiana Kuznetsova, MD, PhD, Division of Hypertension and Cardiac Rehabilitation, Department of Cardiovascular Diseases, University of Leuven, Campus Sint Rafaël, Kapucijnenvoer 35, block d, level 00, Box 7001, B-3000 Leuven, Belgium. E-mail: tatiana.kouznetsova@med.kuleuven.be

Received 3 May 2011 Revised 25 October 2011 Accepted 28 October 2011 J Hypertens 30:403-410 (C) 2012 Wolters Kluwer Health | Lippincott Williams \& Wilkins.

DOI:10.1097/HJH.0b013e32834ea41b
} 
strain rate curves can be calculated by comparing local myocardial velocity profiles [7]. To our knowledge, no population study described the association of the radial and longitudinal left ventricular strain with different blood pressure (BP) components in continuous analyses. We therefore investigated these associations in patients recruited from general population in the framework of the family-based European Project on Genes in Hypertension (EPOGH).

\section{METHODS}

\section{Study participants}

EPOGH was conducted according to the principles outlined in the Helsinki declaration for investigations in humans [8]. The Ethics Committee of each institution approved the protocol. Participants provided informed consent. Three EPOGH centers opted to take part in the echocardiographic substudy. They randomly recruited nuclear families from the general population, including offspring with a minimum age of 18 years. Overall, the response rate was $61.3 \%$ [9].

Our study population consisted of 370 individuals, who in 2006-2008 underwent the echocardiographic examination in Gdansk $(n=112)$ and Cracow $(n=148)$, Poland, and Novosibirsk, the Russian Federation $(n=110)$. We excluded 14 individuals from statistical analysis, because of myocardial infarction or coronary revascularization $(n=3)$, because of moderate-to-severe valvular abnormalities $(n=7)$, or because of atrial fibrillation $(n=4)$. Because the color Doppler myocardial images were of insufficient quality, we additionally discarded 22 individuals from the analysis of left ventricular longitudinal strain and 52 individuals from the analysis of left ventricular radial strain, leaving 334 and 304 participants, respectively.

\section{Echocardiography}

The participants refrained from smoking, heavy exercise, and drinking alcohol or caffeine-containing beverages for at least $3 \mathrm{~h}$ before echocardiography.

\section{Data acquisition}

In each center, one experienced physician (W.S., M.L., A.R.) did the ultrasound examination, using a Vivid7 Pro (GE Vingmed, Horten, Norway) interfaced with a 2.5-3.5-MHz phased-array probe, according to a standardized protocol as previously described [10]. With the individuals in partial left decubitus and breathing normally, the observer obtained images, together with a simultaneous ECG signal, from the parasternal long and short axes and from the apical four-chamber, two-chamber and long-axis views. All recordings included at least five cardiac cycles and were digitally stored for off-line analysis. M-mode echocardiograms of the left ventricle were recorded from the parasternal long-axis view under control of the two-dimensional image. The ultrasound beam was positioned just below the mitral valve at the level of the posterior chordae tendineae.

Using TDI, the observer recorded low-velocity, highintensity myocardial signals at a high frame rate $(>190$ frames/s) while adjusting the imaging angle to ensure a parallel alignment of the ultrasound beam with the myocardial segment of interest. The Nyquist limit was set as low as possible to avoid aliasing.

\section{Off-line analysis}

Digitally stored images were transferred to the Coordinating Center in Leuven for further postprocessing. One experienced observer analyzed the echocardiographic images, using a workstation running the EchoPac, version 4.0.4 (GE Vingmed) software package. We averaged three heart cycles for statistical analysis. The left ventricular internal diameter and interventricular septal and posterior wall thickness were measured at end diastole from the twodimensionally guided M-mode tracing, as described in the American Society of Echocardiography guideline [11]. Enddiastolic left ventricular dimensions were used to calculate left ventricular mass by an anatomically validated formula. Relative wall thickness (RWT) was calculated as the ratio of (interventricular septum + posterior wall thickness)/left ventricular internal diameter at end diastole. Left ventricular end-systolic and end-diastolic volumes and ejection fraction were calculated using Teicholtz's method.

We extracted strain and strain rate curves off-line from color tissue Doppler images, using research-dedicated software as previously described [10]. The SPEQLE software (version 4.6.2, University of Leuven, Belgium) allows Mmode tracking of the myocardium to ensure that the sample volume is maintained in the same anatomical position within myocardial image throughout the cardiac cycle. Moreover, it also allows the accurate implementation of timing of global mechanical events into the deformation curves. We positioned the sampling volume in the basal portion of the interrogated wall at the level of the posterior chordae tendineae. To compute end-systolic strain and peak systolic strain rate, from now on referred to as strain and strain rate, we averaged three consecutive cycles. We calculated the radial strain rate of the posterior wall and the longitudinal strain rate of the inferior and posterior walls, by measuring the spatial velocity gradient over a computation area of 5 and $10 \mathrm{~mm}$, respectively. Strain profiles were obtained by integrating the mean strain rate profile over time [7]. The beginning and ending of the ejection phase were determined from the simultaneously recorded ECG and the continuous-wave Doppler velocity trace at the level of the aortic valve. We used lateral averaging of three to five beams per pixel. Because there were no differences between the posterior and inferior walls in longitudinal strain and strain rate, for statistical analysis, we averaged these measurements and used their absolute values.

As reported previously [10], the interobserver reproducibility was 15.8 and $18.3 \%$ for longitudinal and radial strain and $16.7-14.0 \%$ for longitudinal and radial strain rate, respectively.

\section{Blood pressure measurements}

Trained observers measured BP with a standard mercury sphygmomanometer five times consecutively at the examination center. Standard cuffs had a $12 \mathrm{~cm} \times 24 \mathrm{~cm}$ inflatable bladder, but, if upper arm circumference exceeded $31 \mathrm{~cm}$, larger cuffs with a $15 \mathrm{~cm} \times 35 \mathrm{~cm}$ bladder were used. After at least $10 \mathrm{~min}$ rest, five consecutive $\mathrm{BP}$ readings were 
obtained in the sitting position with an interval of 30-60 s between readings. The cuff was deflated at approximately $2 \mathrm{mmHg} / \mathrm{s}$, and SBP and phase V DBP were recorded to the nearest $2 \mathrm{mmHg}$. Hypertension was defined as a BP of at least $140 \mathrm{mmHg}$ systolic or $90 \mathrm{mmHg}$ diastolic or as the use of antihypertensive drugs. Pulse pressure (PP) was SBPDBP. Mean arterial pressure (MAP) was DBP plus one-third of PP.

\section{Other measurements}

We administered a standardized questionnaire to collect detailed information on each participant's medical history, smoking and drinking habits, and intake of medications. BMI was weight in kilograms divided by the square of height in meters. Waist and hip circumferences were measured to the nearest centimeter with a tape measure while the individual was standing.

\section{Statistical methods}

For database management and statistical analysis, we used SAS software, version 9.2 (SAS Institute, Cary, North Carolina, USA). The central tendency and the spread of the data are reported as mean \pm SD. We compared means and proportions by means of a large sample $z$-test and by the $\chi^{2}$-test, respectively. Significance was $P$ less than 0.05 on two-sided test. While accounting for center, we performed stepwise multiple regression to assess the independent correlations of strain and strain rate with sex, age, anthropometric characteristics [height, weight, BMI, waist circumference, and waist-to-hip ratio (WHR)] and heart rate. We set the $P$ values for variables to enter and to stay in the regression models at 0.10 . Next, we tested the multivariable-adjusted associations between left ventricular systolic function indexes and BP components using a mixed model. This technique allows accounting for covariables as well as for the nonindependence of observations within families. The indexes of left ventricular function and the BP components were analyzed as continuous variables. We ran regression diagnostics to exclude the possibility that collinearity inappropriately influenced our multivariable models. In linear regression, we computed the variance inflation factor (VIF). In single BP component models, VIFs were less than 2.00 for all explanatory variables including BP component (models 1, 2, 4, and 5) with the exception of VIF for the WHR in relation to longitudinal velocity $(\mathrm{VIF}=2.51)$. In multiple regression models, which included simultaneously two BPs components (models 3 and 6), VIF were 2.86 and 2.62 for SBP and DBP, and 1.48 and 1.84 for $\mathrm{PP}$ and MAP, respectively.

\section{RESULTS}

\section{Characteristics of participants}

The 334 participants included 185 (55.4\%) women and 157 (47.0\%) hypertensive patients, 92 (27.5\%) of whom were on antihypertensive drug treatment. Tables 1 and 2, respectively, show the clinical and echocardiographic characteristics of the participants by generation and sex. The mean age of the parents and offspring $( \pm$ SD) was $57.4 \pm 7.6$ and $30.4 \pm 6.7$ years, respectively. In comparison with offspring, parents had higher BMI, WHR, BP, and more frequently reported use of antihypertensive drugs $(P<0.0001$ for all comparisons). The echocardiographic measurements reflecting left ventricular wall thickness and left ventricular mass index (Table 2) were greater in men than in women in both generations. In the parent generation, ejection fraction was greater in women in comparison with men $(P=0.0007)$.

\section{Systolic strain, strain rate, and velocity}

In all participants, strain averaged 20.9\% [95\% confidence interval (CI) 15.5-26.7] longitudinal and 51.1\% (95\% CI $32.5-68.8 \%)$ radial. Strain rate averaged $1.29 \mathrm{~s}^{-1}(0.89-$ $\left.1.85 \mathrm{~s}^{-1}\right)$ longitudinal and $3.40 \mathrm{~s}^{-1}\left(1.94-5.18 \mathrm{~s}^{-1}\right)$ radial.

TABLE 1. General characteristics by generation and sex

\begin{tabular}{|c|c|c|c|c|c|c|}
\hline \multirow[b]{2}{*}{ Characteristic } & \multicolumn{2}{|c|}{ Parents } & \multirow[b]{2}{*}{$P$} & \multicolumn{2}{|c|}{ Offspring } & \multirow[b]{2}{*}{$P$} \\
\hline & Women $(n=97)$ & Men $(n=66)$ & & Women $(n=88)$ & Men $(n=83)$ & \\
\hline \multicolumn{7}{|l|}{ Anthropometrics } \\
\hline Age (years, mean $\pm S D$ ) & $57.1 \pm 7.7$ & $57.9 \pm 7.6$ & 0.52 & $30.8 \pm 7.5$ & $29.9 \pm 6.7$ & 0.40 \\
\hline Weight $(\mathrm{kg}$, mean $\pm \mathrm{SD})$ & $75.9 \pm 14.4$ & $86.4 \pm 14.1$ & $<0.0001$ & $64.9 \pm 14.5$ & $84.5 \pm 16.0$ & $<0.0001$ \\
\hline Height $(\mathrm{cm}$, mean \pm SD) & $160.1 \pm 5.4$ & $172.4 \pm 6.0$ & $<0.0001$ & $165.6 \pm 5.0$ & $177.1 \pm 7.5$ & $<0.0001$ \\
\hline $\mathrm{BMI}\left(\mathrm{kg} / \mathrm{m}^{2}\right.$, mean $\left.\pm \mathrm{SD}\right)$ & $29.6 \pm 5.0$ & $29.1 \pm 4.4$ & 0.50 & $23.7 \pm 5.2$ & $26.8 \pm 4.4$ & $<0.0001$ \\
\hline Waist circumference $(\mathrm{cm}$, mean $\pm \mathrm{SD})$ & $91.2 \pm 11.9$ & $100.5 \pm 11.3$ & $<0.0001$ & $77.7 \pm 12.5$ & $92.5 \pm 12.0$ & $<0.0001$ \\
\hline Waist-to-hip ratio (mean \pm SD) & $0.84 \pm 0.07$ & $0.97 \pm 0.06$ & $<0.0001$ & $0.78 \pm 0.07$ & $0.91 \pm 0.06$ & $<0.0001$ \\
\hline $\mathrm{SBP}(\mathrm{mmHg}$, mean $\pm \mathrm{SD})$ & $139.5 \pm 20.4$ & $145.1 \pm 20.0$ & 0.09 & $119.4 \pm 16.4$ & $131.0 \pm 12.3$ & $<0.0001$ \\
\hline $\mathrm{DBP}(\mathrm{mmHg}$, mean $\pm \mathrm{SD})$ & $85.1 \pm 12.7$ & $87.4 \pm 11.4$ & 0.25 & $76.1 \pm 13.4$ & $78.7 \pm 10.4$ & 0.16 \\
\hline Mean pressure $(\mathrm{mmHg}$, mean $\pm \mathrm{SD})$ & $103.2 \pm 14.2$ & $106.6 \pm 13.4$ & 0.13 & $90.5 \pm 13.9$ & $96.1 \pm 10.0$ & 0.003 \\
\hline Pulse pressure $(\mathrm{mmHg}$, mean $\pm \mathrm{SD})$ & $54.4 \pm 13.9$ & $57.7 \pm 13.3$ & 0.13 & $43.3 \pm 8.3$ & $52.3 \pm 11.0$ & $<0.0001$ \\
\hline Heart rate (beats/min, mean $\pm S D$ ) & $64.5 \pm 8.9$ & $62.7 \pm 10.1$ & 0.25 & $66.3 \pm 9.5$ & $66.0 \pm 10.5$ & 0.87 \\
\hline \multicolumn{7}{|l|}{ Questionnaire data } \\
\hline Current smoking $[n(\%)]$ & $14(14.4)$ & $11(16.7)$ & 0.70 & $24(27.3)$ & $27(32.5)$ & 0.45 \\
\hline Drinking alcohol $[n(\%)]$ & $35(36.1)$ & $36(54.5)$ & 0.02 & $40(45.5)$ & $51(61.5)$ & 0.04 \\
\hline Hypertensive $[n(\%)]$ & $66(68.0)$ & $49(74.2)$ & 0.39 & $14(15.9)$ & $28(33.7)$ & 0.007 \\
\hline Treated for hypertension [ $n(\%)]$ & $47(48.5)$ & $35(53.0)$ & 0.57 & $4(4.5)$ & $6(7.2)$ & 0.46 \\
\hline \multicolumn{7}{|l|}{ Biochemical data } \\
\hline Total cholesterol $(\mathrm{mmol} / \mathrm{l}$, mean $\pm \mathrm{SD})$ & $5.73 \pm 1.01$ & $5.36 \pm 1.08$ & 0.03 & $4.85 \pm 0.97$ & $5.18 \pm 1.38$ & 0.08 \\
\hline Serum creatinine $(\mu \mathrm{mol} / \mathrm{l}$, mean $\pm \mathrm{SD})$ & $70.9 \pm 13.5$ & $91.2 \pm 22.7$ & $<0.0001$ & $66.2 \pm 12.4$ & $85.3 \pm 12.0$ & $<0.0001$ \\
\hline
\end{tabular}


TABLE 2. Echocardiographic measurements by generation and sex

\begin{tabular}{|c|c|c|c|c|c|c|}
\hline \multirow[b]{2}{*}{ Characteristic } & \multicolumn{2}{|c|}{ Parents } & \multirow[b]{2}{*}{$P$} & \multicolumn{2}{|c|}{ Offspring } & \multirow[b]{2}{*}{$P$} \\
\hline & Women $(n=97)$ & Men $(n=66)$ & & Women $(n=88)$ & Men $(n=83)$ & \\
\hline \multicolumn{7}{|l|}{ Conventional echocardiography } \\
\hline LV internal diameter $(\mathrm{cm}$, mean $\pm S D)$ & $4.91 \pm 0.37$ & $5.31 \pm 0.43$ & $<0.0001$ & $4.79 \pm 0.34$ & $5.23 \pm 0.34$ & $<0.0001$ \\
\hline Interventricular septum ( $\mathrm{cm}$, mean $\pm S D$ ) & $1.00 \pm 0.17$ & $1.10 \pm 0.16$ & 0.0003 & $0.81 \pm 0.10$ & $0.96 \pm 0.12$ & $<0.0001$ \\
\hline Posterior wall $(\mathrm{cm}$, mean $\pm \mathrm{SD})$ & $0.90 \pm 0.12$ & $1.00 \pm 0.13$ & $<0.0001$ & $0.76 \pm 0.09$ & $0.90 \pm 0.09$ & $<0.0001$ \\
\hline Relative wall thickness (mean $\pm S D$ ) & $0.39 \pm 0.06$ & $0.40 \pm 0.06$ & 0.55 & $0.33 \pm 0.03$ & $0.36 \pm 0.04$ & $<0.0001$ \\
\hline LV mass index $\left(\mathrm{g} / \mathrm{m}^{2}\right.$, mean $\left.\pm \mathrm{SD}\right)$ & $93.3 \pm 19.6$ & $108.3 \pm 22.1$ & $<0.0001$ & $72.7 \pm 12.8$ & $89.7 \pm 15.3$ & $<0.0001$ \\
\hline Ejection fraction $(\%$, mean $\pm S D)$ & $67.2 \pm 7.0$ & $63.4 \pm 6.2$ & 0.0007 & $62.6 \pm 5.3$ & $62.0 \pm 6.4$ & 0.52 \\
\hline \multicolumn{7}{|l|}{ TDI longitudinal } \\
\hline Strain $(\%$, mean $\pm S D)$ & $21.0 \pm 3.6$ & $20.0 \pm 4.2$ & 0.10 & $22.0 \pm 3.1$ & $20.2 \pm 2.9$ & 0.0001 \\
\hline Strain rate $\left(s^{-1}\right.$, mean $\left.\pm S D\right)$ & $1.27 \pm 0.28$ & $1.28 \pm 0.30$ & 0.84 & $1.33 \pm 0.26$ & $1.29 \pm 0.30$ & 0.41 \\
\hline Systolic velocity $(\mathrm{cm} / \mathrm{s}$, mean $\pm S D)$ & $4.31 \pm 1.1$ & $5.06 \pm 1.5$ & 0.0003 & $5.40 \pm 1.3$ & $6.34 \pm 1.6$ & $<0.0001$ \\
\hline \multicolumn{7}{|l|}{ TDI radial ${ }^{a}$} \\
\hline Strain $(\%$, mean $\pm S D)$ & $49.7 \pm 11.3$ & $46.1 \pm 9.9$ & 0.05 & $54.8 \pm 10.9$ & $52.1 \pm 10.2$ & 0.21 \\
\hline Strain rate $\left(s^{-1}\right.$, mean $\left.\pm S D\right)$ & $3.13 \pm 1.1$ & $3.17 \pm 0.99$ & 0.82 & $3.66 \pm 1.1$ & $3.56 \pm 0.96$ & 0.63 \\
\hline Systolic velocity $(\mathrm{cm} / \mathrm{s}$, mean $\pm S D)$ & $3.40 \pm 1.1$ & $3.69 \pm 1.0$ & 0.13 & $3.78 \pm 0.95$ & $4.23 \pm 0.90$ & 0.004 \\
\hline
\end{tabular}

TDI, tissue Doppler imaging.

a Numbers of women and men are 82 and 56 in the parent generation, and 83 and 83 in the offspring generation, respectively.

Velocity averaged $5.25 \mathrm{~cm} / \mathrm{s}(2.94-8.04 \mathrm{~cm} / \mathrm{s})$ longitudinal and $3.79 \mathrm{~cm} / \mathrm{s}(2.18-5.54 \mathrm{~cm} / \mathrm{s})$ radial.

Table 2 lists the mean values of longitudinal and radial strain and velocities by generation and sex. Among parents, women and men had similar longitudinal strain and strain rate, whereas in the offspring generation, women had significantly greater longitudinal strain than men $(P<0.0001)$. In both generations, the radial strain $(P=0.04)$, but not strain rate $(P=0.95)$ was higher in women than in men. Overall, women had lower longitudinal and radial velocities than men (Table 2).

\section{Covariables of strain, strain rate, and velocities}

Table 3 shows the independent correlates of the longitudinal and radial strain, strain rate, and velocities, as well as ejection fraction as selected by stepwise regression in all subjects. Longitudinal strain significantly decreased with the WHR, and radial strain and strain rate with age and body weight ( $P \leq 0.02$ for all; Table 3 ). Longitudinal and radial systolic velocities significantly and independently decreased with age $(P<0.0001)$ and female sex $(P=0.002)$. While adjusting for covariables, longitudinal and radial strain rate and velocities significantly increased with heart rate $(P \leq 0.009)$. In

TABLE 3. Correlates of longitudinal and radial strain, strain rate, velocities, and ejection fraction selected by stepwise regression

\begin{tabular}{|c|c|c|c|c|c|c|c|}
\hline \multirow[b]{2}{*}{ Parameter } & \multicolumn{3}{|c|}{ Longitudinal } & \multicolumn{3}{|c|}{ Radial } & \multirow[b]{2}{*}{$\begin{array}{l}\mathrm{EF} \\
(\%)\end{array}$} \\
\hline & $\begin{array}{l}\text { Strain } \\
(\%)\end{array}$ & $\begin{array}{l}\text { Strain rate } \\
\left(\mathbf{s}^{-1}\right)\end{array}$ & $\begin{array}{l}\text { Velocity } \\
(\mathrm{cm} / \mathrm{s})\end{array}$ & $\begin{array}{l}\text { Strain } \\
(\%)\end{array}$ & $\begin{array}{l}\text { Strain rate } \\
\left(\mathbf{s}^{-1}\right)\end{array}$ & $\begin{array}{l}\text { Velocity } \\
(\mathrm{cm} / \mathrm{s})\end{array}$ & \\
\hline \multicolumn{8}{|c|}{ Regression statistic } \\
\hline Model $R^{2}$ & 0.11 & 0.05 & 0.29 & 0.13 & 0.12 & 0.19 & 0.10 \\
\hline \multicolumn{8}{|c|}{ Age ( +10 years) } \\
\hline \multirow[t]{2}{*}{$\beta \pm \mathrm{SE}$} & - & - & $-0.30 \pm 0.06$ & $-1.66 \pm 0.41$ & $-0.12 \pm 0.04$ & $-0.15 \pm 0.04$ & $1.10 \pm 0.23$ \\
\hline & & & $P<0.0001$ & $P<0.0001$ & $P=0.002$ & $P<0.0001$ & $P<0.0001$ \\
\hline Partial $r^{2}(\%)$ & & & 17.7 & 7.7 & 4.9 & 6.5 & 6.9 \\
\hline \multicolumn{8}{|l|}{ Female $(0,1)$} \\
\hline \multirow[t]{2}{*}{$\beta \pm \mathrm{SE}$} & - & - & $-1.37 \pm 0.21$ & - & - & $-0.34 \pm 0.11$ & $2.19 \pm 0.71$ \\
\hline & & & $P<0.0001$ & & & $P=0.002$ & $P=0.002$ \\
\hline Partial $r^{2}(\%)$ & & & 7.6 & & & 1.9 & 2.6 \\
\hline \multicolumn{8}{|c|}{ Body weight (+1 kg) } \\
\hline \multirow[t]{2}{*}{$\beta \pm \mathrm{SE}$} & - & - & - & $-0.15 \pm 0.04$ & $-0.007 \pm 0.003$ & - & - \\
\hline & & & & $P<0.0001$ & $P=0.02$ & & \\
\hline \multicolumn{4}{|l|}{ Partial $r^{2}(\%)$} & 4.8 & 1.9 & & \\
\hline \multicolumn{8}{|l|}{ WHR $(+0.1)$} \\
\hline \multirow[t]{2}{*}{$\beta \pm \mathrm{SE}$} & $-0.99 \pm 0.20$ & - & $-0.40 \pm 0.12$ & - & - & - & - \\
\hline & $P<0.0001$ & & $P=0.001$ & & & & \\
\hline Partial $r^{2}(\%)$ & 6.6 & & 1.5 & & & & \\
\hline \multicolumn{8}{|c|}{ Heart rate $(+10$ beats $/ \mathrm{min})$} \\
\hline \multirow[t]{2}{*}{$\beta \pm \mathrm{SE}$} & - & $0.04 \pm 0.016$ & $0.22 \pm 0.08$ & - & $0.16 \pm 0.06$ & $0.23 \pm 0.05$ & - \\
\hline & & $P=0.005$ & $P=0.009$ & & $P=0.005$ & $P<0.0001$ & \\
\hline Partial $r^{2}(\%)$ & & 2.3 & 1.8 & & 1.5 & 4.6 & \\
\hline
\end{tabular}

We performed stepwise multiple regression to assess the independent correlations of strain and strain rate with sex, age, anthropometric characteristics [height, weight, BMI, waist circumference, and waist-to-hip ratio (WHR)] and heart rate. $\beta$ indicates the partial regression coefficients. EF, ejection fraction. Variance inflation factors (VIFs) were less than 2.00 for all explanatory variables with exception of VIF for the WHR in relation to longitudinal velocity $(\mathrm{VIF}=2.51)$. 
TABLE 4. Association between longitudinal systolic function and blood pressure in 334 individuals

\begin{tabular}{|c|c|c|c|c|c|c|c|}
\hline \multirow[b]{2}{*}{ Model } & \multirow[b]{2}{*}{ BP component } & \multicolumn{2}{|l|}{ Strain (\%) } & \multicolumn{2}{|l|}{ Strain rate $\left(\mathbf{s}^{-1}\right)$} & \multicolumn{2}{|l|}{ Velocity $(\mathrm{cm} / \mathrm{s})$} \\
\hline & & $\begin{array}{l}\text { Parameter estimate } \\
\qquad(95 \% \mathrm{Cl})\end{array}$ & $\boldsymbol{P}$ & $\begin{array}{l}\text { Parameter estimate } \\
(95 \% \mathrm{Cl})\end{array}$ & $P$ & $\begin{array}{l}\text { Parameter estimate } \\
(95 \% \mathrm{Cl})\end{array}$ & $P$ \\
\hline Model 1 & Systolic & $-0.41(-0.85$ to 0.024$)$ & 0.06 & $-0.015(-0.053$ to 0.023$)$ & 0.43 & $-0.14(-0.32$ to 0.040$)$ & 0.13 \\
\hline Model 2 & Diastolic & $-0.59(-1.02$ to -0.16$)$ & 0.007 & $-0.025(-0.062$ to 0.013$)$ & 0.20 & $-0.11(-0.28$ to -0.070$)$ & 0.23 \\
\hline \multirow[t]{2}{*}{ Model 3} & Systolic & $0.04(-0.58$ to 0.66$)$ & 0.90 & $0.004(-0.049$ to 0.057$)$ & 0.88 & $-0.12(-0.37$ to 0.13$)$ & 0.34 \\
\hline & Diastolic & $-0.62(-1.23$ to -0.01$)$ & 0.04 & $-0.028(-0.08$ to 0.025$)$ & 0.30 & $-0.023(-0.27$ to 0.22$)$ & 0.85 \\
\hline Model 4 & Pulse pressure & $-0.02(-0.43$ to 0.39$)$ & 0.92 & $0.001(-0.033$ to 0.035$)$ & 0.96 & $-0.084(-0.25$ to 0.078$)$ & 0.31 \\
\hline Model 5 & Mean arterial pressure & $-0.55(-0.97$ to -0.12$)$ & 0.01 & $-0.022(-0.059$ to 0.015$)$ & 0.25 & $-0.13(-0.30$ to -0.047$)$ & 0.15 \\
\hline \multirow[t]{2}{*}{ Model 6} & Pulse pressure & $0.22(-0.21$ to 0.66$)$ & 0.31 & $0.011(-0.026$ to 0.048$)$ & 0.56 & $-0.044(-0.22$ to 0.13$)$ & 0.62 \\
\hline & Mean arterial pressure & $-0.64(-1.10$ to -0.18$)$ & 0.007 & $-0.027(-0.067$ to 0.014$)$ & 0.19 & $-0.11(-0.30$ to 0.080$)$ & 0.25 \\
\hline
\end{tabular}

Parameter estimates [95\% confidence interval (CI)] indicated changes in the left ventricular longitudinal systolic function associated with a 1 SD increase in SBP and DBP, mean arterial pressure, and pulse pressure. All parameter estimates were adjusted for family clusters, center, sex, age, body weight, heart rate, and antihypertensive drug treatment. Model 1 and model 2 included single BP component (SBP or DBP). Model 3 included both BP components (SBP and DBP). Model 4 and model 5 included single BP component (pulse pressure or mean arterial pressure). Model 6 included both pulse pressure and mean arterial pressure.

contrast, ejection fraction significantly and independently increased with age $(P<0.0001)$ and female sex $(P=0.002)$. The explained variance totaled 11.0 and $13.4 \%$ for longitudinal and radial strain, 5.0 and $11.9 \%$ for longitudinal and radial strain rate, and 29 and 19\% for longitudinal and radial velocities, respectively.

\section{Multivariable-adjusted association between left ventricular systolic tissue Doppler imaging indexes with blood pressure components}

The multivariable-adjusted estimates (95\% CI) associated with a 1-SD increase in SBP, DBP, MAP, or PP are shown in Table 4 for the longitudinal and in Table 5 for the radial indexes of left ventricular systolic function. All models were adjusted for family clusters, center, sex, age, body weight, heart rate, and antihypertensive drug treatment. Models 1, 2,4 , and 5 also included one of the blood pressure components (SBP, DBP, PP, or MAP). Models 3 and 6 included both SBP and DBP or both PP and MAP, respectively.

In single $\mathrm{BP}$ component models, longitudinal strain, but not strain rate or velocity, decreased with higher DBP $(P=0.007$; model 2 in Table 4$)$ and MAP $(P=0.01$; model 5 in Table 4 ). The inverse association between longitudinal strain and DBP remained significant $(P=0.04)$ in model 3, which additionally included SBP. The association between longitudinal strain and MAP also remained significant $(P=0.007)$ in model 6 , which further adjusted for PP (Table 4).
In multivariable-adjusted models, radial systolic strain and strain rate significantly increased with SBP $(P \leq 0.03$; model 1 in Table 5). In model 3, which included both SBP and DBP components (Table 5), both BP components were significantly correlated with radial strain and strain rate and the effects were opposite in direction. These associations were positive for SBP $(P<0.0001)$ and negative for DBP $(P \leq 0.04)$. Accordingly, radial strain $(P<0.0001)$ and strain rate $(P \leq 0.0005)$ were associated with higher PP even if MAP was added to the PP model (Table 5). Radial velocity was directly correlated with DBP $(P=0.003)$ and MAP $(P \leq 0.003$; Table 5).

Figure 1 shows radial strain (panel a) and strain rate (panel b) in relation to SBP at various levels of DBP in continuous analyses adjusted for the covariables. At any given level of SBP, radial strain $(P=0.001)$ and strain rate $(P=0.04)$ increased with lower DBP, again confirming that left ventricular systolic radial function was directly and independently associated with PP.

In sensitivity analysis including only 254 untreated patients, our findings remained consistent. Longitudinal systolic strain $(P=0.01)$ decreased significantly with MAP, whereas radial strain $(P=0.0005)$ and strain rate $(P=0.03)$ increased with PP (Supplemental Tables S1 and S2, http://links.lww.com/HJH/A143).

We also observed a direct association between radial strain and central PP in analyses including a subgroup of 206 patients from Gdansk and Cracow, in whom we

TABLE 5. Association between radial systolic function and blood pressure in 304 individuals

\begin{tabular}{|c|c|c|c|c|c|c|c|}
\hline \multirow[b]{2}{*}{ Model } & \multirow[b]{2}{*}{ BP component } & \multicolumn{2}{|l|}{ Strain (\%) } & \multicolumn{2}{|c|}{ Strain rate $\left(\mathbf{s}^{-1}\right)$} & \multicolumn{2}{|c|}{ Velocity (cm/s) } \\
\hline & & $\begin{array}{l}\text { Parameter estimate } \\
(95 \% \mathrm{CI})\end{array}$ & $P$ & $\begin{array}{l}\text { Parameter estimate } \\
(95 \% \mathrm{Cl})\end{array}$ & $P$ & $\begin{array}{l}\text { Parameter estimate } \\
(95 \% \mathrm{Cl})\end{array}$ & $P$ \\
\hline Model 1 & Systolic & $1.68(0.17$ to 3.19$)$ & 0.03 & $0.26(0.12$ to 0.39$)$ & 0.0002 & 0.18 (0.047 to 0.31$)$ & 0.008 \\
\hline Model 2 & Diastolic & $-0.61(-2.14$ to 0.93$)$ & 0.44 & $0.078(-0.06$ to 0.22$)$ & 0.27 & 0.21 (0.07 to 0.34 ) & 0.003 \\
\hline \multirow[t]{2}{*}{ Model 3} & Systolic & 4.01 (2.01 to 6.01$)$ & 0.0001 & $0.38(0.20$ to 0.55$)$ & $<0.0001$ & $0.08(-0.10$ to 0.26$)$ & 0.41 \\
\hline & Diastolic & $-3.38(-5.41$ to -1.36$)$ & 0.001 & $-0.18(-0.35$ to -0.002$)$ & 0.04 & $0.15(-0.03$ to 0.34$)$ & 0.10 \\
\hline Model 4 & Pulse pressure & 2.57 (1.27 to 3.87$)$ & 0.0001 & $0.25(0.13$ to 0.36$)$ & $<0.0001$ & $0.06(-0.06$ to 0.18$)$ & 0.33 \\
\hline Model 5 & Mean arterial pressure & $0.42(-1.10$ to 1.94$)$ & 0.58 & $0.17(0.034$ to 0.31$)$ & 0.01 & 0.21 (0.07 to 0.34$)$ & 0.002 \\
\hline \multirow[t]{2}{*}{ Model 6} & Pulse pressure & 2.87 (1.45 to 4.28$)$ & $<0.0001$ & $0.22(0.10$ to 0.35$)$ & 0.0005 & $-0.02(-0.15$ to 0.11$)$ & 0.78 \\
\hline & Mean arterial pressure & $-0.84(-2.45$ to 0.77$)$ & 0.31 & $0.07(-0.07$ to 0.21$)$ & 0.33 & $0.22(0.07$ to 0.36$)$ & 0.003 \\
\hline
\end{tabular}

Parameter estimates [95\% confidence interval (CI)] indicated changes in the left ventricular radial systolic function associated with a 1 SD increase in SBP and DBP, mean arterial pressure, and pulse pressure. All parameter estimates were adjusted for family clusters, center, sex, age, body weight, heart rate, and antihypertensive drug treatment. Model 1 and model 2 included single BP component (SBP or DBP). Model 3 included both BP components (SBP and DBP). Model 4 and model 5 included single BP component (pulse pressure or mean arterial pressure). Model 6 included both pulse pressure and mean arterial pressure. 
Panel a

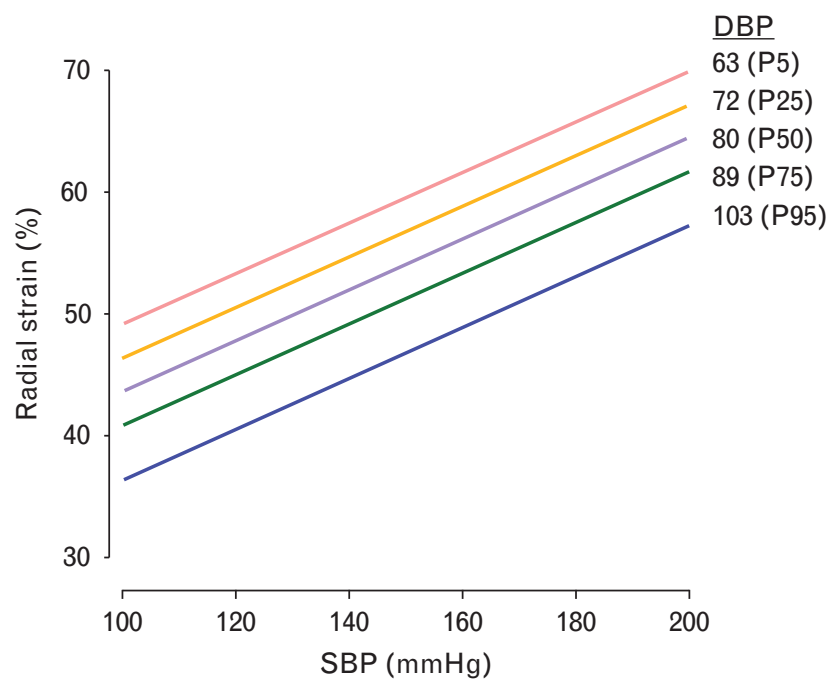

Panel b

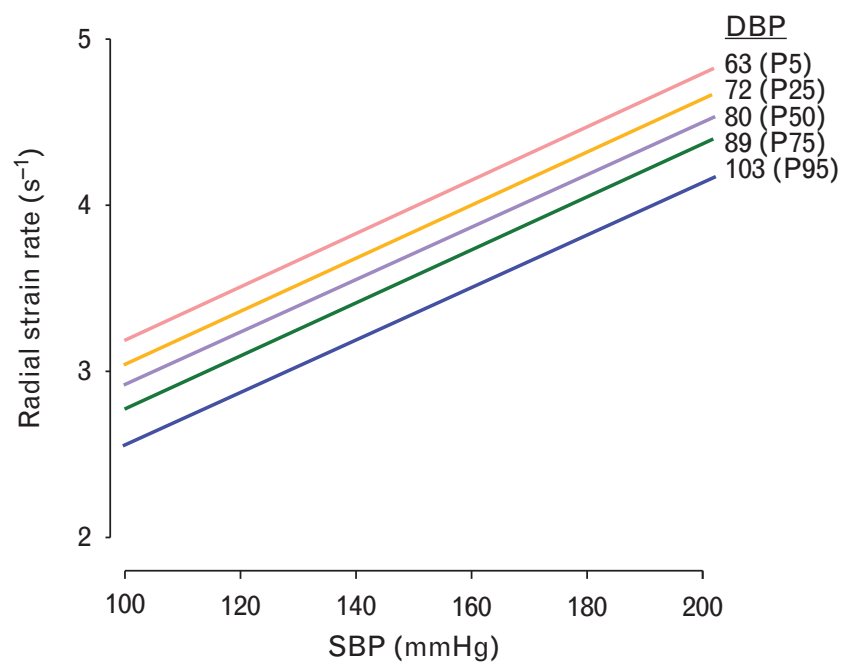

FIGURE 1 Extrapolation from the multivariable-adjusted model of radial strain (panel a) and strain rate (panel b) in relation to the SBP at fixed levels of DBP. The numbers at the extrapolation lines indicate the fixed levels of DBP. P5, P25, P50, P75, and P95 are percentiles of the DBP distribution.

measured central hemodynamics using applanation tonometry (see Supplemental methods and Supplemental Table S3, http://links.lww.com/HJH/A143). The multivariable-adjusted association between left ventricular radial strain and central PP was similar compared with the association seen with peripheral PP (Supplemental Table S4, http://links.lww.com/HJH/A143).

\section{DISCUSSION}

The main finding of our study was that the steady and pulsatile components of BP were differently associated with the longitudinal and radial components of left ventricular systolic function. Radial left ventricular systolic function increased with the pulsatile component of BP as assessed by PP. Longitudinal left ventricular systolic function decreased with MAP and DBP. Thus, hemodynamic factors, such as a chronic pulsatile hemodynamic loading on the left ventricular and longstanding high MAP, impact on left ventricular systolic function.

The steady component of BP, represented by MAP and the pulsatile component, represented by $\mathrm{PP}$, play an important role in the pathophysiology of cardiovascular diseases [12]. MAP is determined by peripheral arterial resistance, which depends on the physical characteristics of the arterial tree and the volume of blood that the left ventricular ejects. In the absence of aortic stenosis, BP provides a clinically useful estimate of left ventricular afterload. There is a relation between left ventricular stroke volume and aortic compliance in the determination of central and peripheral PP. On one hand, if aorta is noncompliant, the greater the left ventricular stroke volume, the greater the changes in aortic systolic pressure during left ventricular ejection and, hence, the higher the aortic PP becomes. On the other hand, if the aorta is compliant, the aortic walls elastically expand to accommodate the ejected blood during systole. An elastic aorta, therefore, dampens pulsatility and maintains a continuous blood flow from the heart to the periphery. In other words, aortic PP reflects pulsatile stress and aortic rigidity [13]. Furthermore, PP is amplified with increasing distance from the aortic root especially in younger patients [14]. Thus, peripheral (brachial) PP is not always the perfect surrogate for aortic PP. Relationships between an elevated peripheral PP and left ventricular hypertrophy [15], impaired left ventricular relaxation [16], and symptomatic heart failure [17,18] have been reported previously. On the contrary, recent clinical studies [19-22] have also demonstrated that left ventricular mass, left ventricular diastolic function, and intima-media thickness were more strongly related to central pressures than to peripheral pressures. However, a recent metaanalysis provided no evidence that aortic PP is predictive of cardiovascular mortality and morbidity over and beyond pressures measured at periphery [23].

The heart is a complex three-dimensional structure consisting of myocytes laid out in different directions [24]. Longitudinal movement of the left ventricular results from contraction of longitudinally oriented subendocardial and subepicardial fibers, whereas radial left ventricular wall thickening mainly originates from contraction of circumferential fibers located in the mid-wall [24]. Gould et al. [25] assessed the relation between the directional components of left ventricular contraction and ejection fraction in 122 patients with or without heart disease, by using angiocardiography. The contribution of the longitudinal and radial components to total cardiac work was 14 and 40\%, respectively [25]. In other words, the radial function builds up the pressure, whereas the longitudinal function serves more to accommodate the 'volume' load of the left ventricle. Thus, separate analysis of the various components of left ventricular systolic function might be important for understanding the progression of left ventricular systolic dysfunction at different stages of heart disease [26].

In our study, the multivariable-adjusted longitudinal strain, strain rate, and velocity significantly decreased with higher MAP. Along similar lines, some clinical studies found depressed left ventricular longitudinal function in patients with hypertension as compared with normotensive controls 
[1-4,27,28]. Baltabaeva et al. [4] reported an inverse correlation between longitudinal basal strain and MAP in 74 untreated hypertensive patients and 34 normotensive individuals. Changes in left ventricular deformation are determined by the fiber structure and curvature of the myocardium and its interaction with local wall stress at the beginning of ejection, which decreases from the endocardium to epicardium and from the left ventricular base to the apex [29]. Thus, increased MAP might lead to increased wall stress, particularly on the longitudinally oriented and less curved subendocardial fibers. Since the subendocardium is more vulnerable to increased wall stress, ischemia, and interstitial fibrosis, longitudinal systolic dysfunction could already been seen at the early stages of progressive myocardial disease, including hypertrophy and myocardial ischemia [30].

A recent experimental study involving an aortic banding model showed disparate changes in longitudinal and radial myocardial strain in response to acute alternations to left ventricular afterload [31]. Longitudinal systolic function dramatically fell as afterload increased, whereas left ventricular fractional shortening and radial strain were still preserved after a mild banding [31]. Along similar lines, previous studies in patients with hypertension or diabetes showed that the decreased longitudinal function appears to be compensated by increased radial function [1-4,32]. The precise mechanism of the radial compensation in these patients remains unclear. One possible explanation might be linked to left ventricular wall stress. Because of differences in the left ventricular curvature, left ventricular wall stress is usually lower circumferentially than longitudinally [29]. Thus, at higher pressures, longitudinal wall stress is increased, which impairs deformation of the myofibers in this direction. To maintain stroke volume under these conditions, circumferential fibers take over part of the cardiac work. In line with this mechanism, left ventricular radial systolic function increased with higher systolic pressure. In addition, the multivariable-adjusted model showed that at any given level of SBP, radial strain and strain rate also increased with lower DBP. Thus, chronic increase in PP increases left ventricular load and enhances left ventricular radial systolic performance, and might in long run lead to left ventricular hypertrophy and increase in left ventricular oxygen requirements. This mechanism probably contributes to development and progression of left ventricular dysfunction in hypertensive patients.

In our study, we described the association of the radial and longitudinal left ventricular strain with steady and pulsatile BP components measured at the brachial artery. Whereas MAP and DBP almost do not change from the aortic root to brachial artery, PP is more dynamic and is amplified with increasing distance from the aortic root, especially in younger individuals. Thus, it might seem likely that aortic (central) PP should demonstrate a more significant association with left ventricular function than brachial (peripheral) PP. To address this issue, we also analyzed the association between left ventricular radial strain and central PP in a subgroup of 206 individuals. We found that the association of left ventricular radial strain with central PP was similar to the association with peripheral (brachial) PP (as the effect sizes were 2.26 vs. $2.57 \%$, respectively).
The present study must be interpreted within the context of its potential limitations and strengths. First, strain and strain rate TDI imaging is prone to measurement error due to signal noise, acoustic artifacts, and angle dependency. This may limit the application of TDI in routine clinical practice. Newer techniques, such as 'speckle tracking' algorithms, might be less vulnerable to these artifacts [33]. However, TDI offers superior temporal resolution, which is important particularly in assessing the radial component of left ventricular systolic function, in comparisons with speckle tracking or MRI techniques. Second, although we optimized the angle of the ultrasound beam, the velocity range settings and noise level, we could not always acquire images of optimal quality, especially for assessment of radial strain and strain rate. Thus, we had to discard 52 individuals from the analysis of radial strain. Left ventricular axis deviation (older individuals) and a thinner myocardial wall (younger individuals) often lead to nonperpendicular alignment of the ultrasound beam or artifacts due to endocardial and epicardial reflections, respectively. These factors reduce the accuracy of the TDI technique in the assessment of the radial strain. Third, we estimated longitudinal strain and strain rate only from the basal segment of the inferior and inferolateral left ventricular free walls. We might therefore have underestimated the full spectrum of longitudinal or radial deformation along and between the left ventricular walls. However, the objective of our study was to explore the effects of different BP components on radial and longitudinal left ventricular strain measured at the same segment of the left ventricular wall and, therefore, clarify the possible mechanism that might contribute to development and progression of left ventricular dysfunction associated with higher PP. Finally, BP was measured in the seated position, whereas echocardiography for left ventricular systolic function was recorded at the same day but at a different time point in the partial left lateral decubitus position. However, the results on association between left ventricular radial strain and sitting brachial BPs were similar compared with the associations seen with supine central pressures or supine brachial BPs in a subgroup of 206 individuals in whom both supine and sitting BP measurements were available (Supplemental Table S4, http://links.lww.com/HJH/A143).

In conclusion, our study is the first to describe in a general population the association of radial and longitudinal left ventricular strain with various BP components analyzed on a continuous scale. We demonstrated that left ventricular radial function increased with $\mathrm{PP}$, the pulsatile BP component, whereas longitudinal function decreased with the steady component of BP as expressed by MAP or DBP. It sets the agenda for clinical practice and research. From the clinical point of view, our study underscores the importance of BP, particularly PP, as the mediator of left ventricular systolic dysfunction. In an era in which isolated systolic hypertension affects about 30\% of the elderly (60 years), controlling BP to target levels is of paramount importance to block the transition from left ventricular dysfunction to overt heart failure. From the research point of view, further studies should clarify the mechanism underlying the increase in left ventricular radial strain in response to SBP and $\mathrm{PP}$ and the decrease in longitudinal 
strain in response to MAP. Clarifying these mechanisms might open new opportunities for prevention and treatment of early left ventricular dysfunction.

\section{ACKNOWLEDGEMENTS}

The European Project on Genes in Hypertension (EPOGH) investigators are listed in the online Data Supplement, http://links.lww.com/HJH/A143.

The European Union (grants IC15-CT98-0329-EPOGH, LSHM-CT-2006-037093 InGenious HyperCare, and HEALTH-F4-2007-201550 HyperGenes) supported the Studies Coordinating Centre (Leuven, Belgium) and the studies Padova (Italy), Novosibirsk (Russian Federation), Kraków and Gdansk (Poland). The Studies Coordinating Centre also received grants from the Fonds voor Wetenschappelijk Onderzoek Vlaanderen, Ministry of the Flemish Community, Brussels, Belgium (grants G.0575.06 and G.0734.09). The Foundation for Polish Science (grants TEAM/2008-2/5 and MISTRZ 8/2008) supported the studies in Gdansk.

\section{Conflicts of interest}

There are no conflicts of interest.

\section{REFERENCES}

1. Przewlocka-Kosmala M, Kosmala W, Mazurek W. Left ventricular circumferential function in patients with essential hypertension. J Hum Hypertens 2006; 20:666-671.

2. Kosmala W, Plaksej R, Strotmann JM. Progression of left ventricular functional abnormalities in hypertensive patients with heart failure: an ultrasonic two-dimensional speckle tracking study. J Am Soc Echocardiogr 2008; 21:1309-1317.

3. Ballo P, Quatrini I, Giacomin E, Motto A, Mondillo S. Circumferential versus longitudinal systolic function in patients with hypertension: a nonlinear relation. J Am Soc Echocardiogr 2007; 20:298-306.

4. Baltabaeva A, Marciniak M, Bijnens B, Moggridge J, He FJ, Antonios TF, et al. Regional left ventricular deformation and geometry analysis provides insights in myocardial remodelling in mild to moderate hypertension. Eur J Echocardiogr 2008; 9:501-508.

5. Aurigemma GP, Silver KH, Priest MA, Gaasch WH. Geometric changes allow normal ejection fraction despite depressed myocardial shortening in hypertensive left ventricular hypertrophy. J Am Coll Cardiol 1995; 26:195-202.

6. Palmon LC, Reichek N, Yeon SB, Clark NR, Brownson D, Hoffman E, Axel L. Intramural myocardial shortening in hypertensive left ventricular hypertrophy with normal pump function. Circulation 1994; 89:122-131.

7. D'Hooge J, Heimdal A, Jamal F, Kukulski T, Bijnens B, Rademakers FE, et al. Regional strain and strain rate measurements by cardiac ultrasound: principles, implementation and limitations. Eur J Echocardiogr 2000; $1: 154-170$.

8. 41st World Medical Assembly: Declaration of Helsinki. Recommendations guiding physicians in biomedical research involving human subjects. Bull Pan Am Health Organ. 1990; 24:606-609.

9. Kuznetsova T, Staessen JA, Thijs L, Kunath C, Olszanecka A, Ryabikov $\mathrm{A}$, et al. Left ventricular mass in relation to genetic variation in angiotensin II receptors, renin system genes, and sodium excretion. Circulation 2004; 110:2644-2650.

10. Kuznetsova T, Herbots L, Richart T, D'hooge J, Thijs L, Fagard RH, et al. Left ventricular strain and strain rate in a general population. Eur Heart J 2008; 29:2014-2023.

11. Gottdiener JS, Bednarz J, Devereux R, Gardin J, Klein A, Manning WJ, et al. American Society of Echocardiography recommendations for use of echocardiography in clinical trials. A report from the American Society of Echocardiography's Guidelines and Standard Committee and the Task Force on Echocardiography in Clinical Trials. J Am Soc Echocardiogr 2004; 17:1086-1119.
12. Darne B, Girerd X, Safar M, Cambien F, Guize L. Pulsatile versus steady component of blood pressure: a cross-sectional analysis and a prospective analysis on cardiovascular mortality. Hypertension 1989; 13:392-400.

13. Safar ME. New problems raised by increased pulse pressure. Eur Heart J 2005; 26:2081-2082.

14. Wojciechowska W, Stolarz-Skrzypek K, Tikhonoff V, Richart T, Seidlerová J, Cwynar M, et al.; on behalf of the European Project On Genes In Hypertension (Epogh) Investigators. Age dependency of central and peripheral systolic blood pressures: cross-sectional and longitudinal observations in European populations. Blood Press 2011; 7. [Epub ahead of print]

15. Gardin JM, Arnold A, Gottdiener JS, Wong ND, Fried LP, Klopfenstein $\mathrm{HS}$, et al. Left ventricular mass in the elderly. The Cardiovascular Health Study. Hypertension 1997; 29:1095-1103.

16. Kuznetsova T, Herbots L, López B, Jin Y, Richart T, Thijs L, et al. Prevalence of left ventricular diastolic dysfunction in a general population. Circ Heart Fail 2009; 2:105-112.

17. Chae CU, Pfeffer MA, Glynn RJ, Mitchell GF, Taylor JO, Hennekens CH. Increased pulse pressure and risk of heart failure in the elderly. JAMA 1999; 281:634-639.

18. Haider AW, Larson MG, Franklin SS, Levy D, Framingham Heart Study. Systolic blood pressure, diastolic blood pressure, and pulse pressure as predictors of risk for congestive heart failure in the Framingham Heart Study. Ann Intern Med 2003; 138:10-16.

19. Wang KL, Cheng HM, Chuang SY, Spurgeon HA, Ting CT, Lakatta EG, et al. Central or peripheral systolic or pulse pressure: which best relates to target organs and future mortality? J Hypertens 2009; 27:461-467.

20. Weber T, O'Rourke MF, Ammer M, Kvas E, Punzengruber C, Eber B. Arterial stiffness and arterial wave reflections are associated with systolic and diastolic function in patients with normal ejection fraction. Am J Hypertens 2008; 21:1194-1202.

21. Roman MJ, Okin PM, Kizer JR, Lee ET, Howard BV, Devereux RB. Relations of central and brachial blood pressure to left ventricular hypertrophy and geometry: the Strong Heart Study. J Hypertens 2010; 28:384-388.

22. Shim CY, Park S, Choi D, Yang WI, Cho IJ, Choi EY, et al. Sex differences in central hemodynamics and their relationship to left ventricular diastolic function. J Am Coll Cardiol 2011; 57:1226-1233.

23. Vlachopoulos C, Aznaouridis K, O'Rourke MF, Safar ME, Baou K, Stefanadis C. Prediction of cardiovascular events and all-cause mortality with central haemodynamics: a systematic review and meta-analysis. Eur Heart J 2010; 31:1865-1871.

24. Spotnitz HM. Macro design, structure, and mechanics of the left ventricle. J Thorac Cardiovasc Surg 2000; 119:1053-1077.

25. Gould KL, Kennedy JW, Frimer M, Pollack GH, Dodge HT. Analysis of wall dynamics and directional components of left ventricular contraction in man. Am J Cardiol 1976; 38:322-331.

26. Sengupta PP. Left ventricular transmural mechanics: tracking opportunities in-depth. J Am Soc Echocardiogr 2009; 22:1022-1024.

27. Kang SJ, Lim HS, Choi BJ, Choi SY, Hwang GS, Yoon MH, et al. Longitudinal strain and torsion assessed by two-dimensional speckle tracking correlate with the serum level of tissue inhibitor of matrix metalloproteinase-1, a marker of myocardial fibrosis, in patients with hypertension. J Am Soc Echocardiogr 2008; 21:907-911.

28. Di Bello V, Talini E, Dell'Omo G, Giannini C, Delle Donne MG, Canale ML, et al. Early left ventricular mechanics abnormalities in prehypertension: a two-dimensional strain echocardiography study. $\mathrm{Am} \mathrm{J}$ Hypertens 2010; 23:405-412.

29. Choi HF, D'hooge J, Rademakers FE, Claus P. Distribution of active fiber stress at the beginning of ejection depends on left-ventricular shape. Conf Proc IEEE Eng Med Biol Soc 2010; 2010:2638-2641.

30. Sengupta PP, Narula J. Reclassifying heart failure: predominantly subendocardial, subepicardial, and transmural. Heart Fail Clin 2008; 4:379382.

31. Donal E, Bergerot C, Thibault H, Ernande L, Loufoua J, Augeul L, et al . Influence of afterload on left ventricular radial and longitudinal systolic functions: a two-dimensional strain imaging study. EurJ Echocardiogr 2009; 10:914-921.

32. Fang ZY, Leano R, Marwick TH. Relationship between longitudinal and radial contractility in subclinical diabetic heart disease. Clin Sci (Lond) 2004; 106:53-60.

33. Geyer H, Caracciolo G, Abe H, Wilansky S, Carerj S, Gentile F, et al. Assessment of myocardial mechanics using speckle tracking echocardiography: fundamentals and clinical applications. J Am Soc Echocardiogr 2010; 23:351-369. 